\title{
Molecular inhibition mechanisms of cell migration and invasion by coix polysaccharides in A549 NSCLC cells via targeting S100A4
}

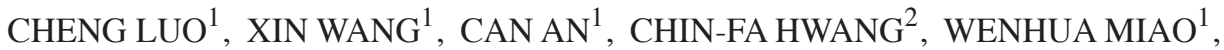 \\ $\mathrm{LU} \mathrm{YANG}^{3}$, MAONIAN XU ${ }^{4}$, AIPING BAI ${ }^{5}$ and SHANGGUI DENG ${ }^{1}$
}

\author{
${ }^{1}$ School of Food and Pharmacy, Zhejiang Ocean University, Zhoushan, Zhejiang 316022, P.R. China; \\ ${ }^{2}$ Department of Food Science and Technology, Hung Kuang University, Taichung 43302, Taiwan, R.O.C.; \\ ${ }^{3}$ Division of Pharmacognosy, Department of Medicinal Chemistry, Biomedical Center, University of Uppsala, 75123 Uppsala, \\ Sweden; ${ }^{4}$ Department of Food and Environmental Sciences, Division of Food Chemistry, University of Helsinki, F-00014 Helsinki, \\ Finland; ${ }^{5}$ Department of Medicine, Beth Israel Deaconess Medical Center, Harvard University, Boston, MA 02215, USA
}

Received April 21,2016; Accepted October 21, 2016

DOI: $10.3892 / \mathrm{mmr} .2016 .5985$

\begin{abstract}
S100 calcium binding protein A4 (S100A4) promotes extracellular signal transduction, intercellular adhesion, motility and mobility. Different extracts from Coix lachryma-jobi have been used for the treatment of various types of cancer in Asia. In our previous study, the polysaccharide fraction extact, CP1, induced cell apoptosis of non-small cell lung cancer cells. In the current study, CP1 inhibited migration and invasion of A549 cells in a scratch wound healing assay and matrigel invasion assay, respectively. Furthermore, reverse transcription-polymerase chain reaction and western blotting demonstrated that CP1 downregulated the gene and protein expression levels of S100A4. In silico docking analysis demonstrated that polysaccharides may not interfere with dimerization, whereas, the affinity of polysaccharides for an S100A4-NMIIA pocket was margnially greater than at the dimerization sites. Thus, CP1 inhibited A549 cell migration and invasion potentially via downregulation of S100A4, and may also interact with the binding site of S100A4-NMIIA, which indicated that $\mathrm{CP} 1$ has potential as an alternative cancer chemotherapeutic by targeting S100A4.
\end{abstract}

\section{Introduction}

S100 genes include at least 19 members of a calcium-binding protein family, which are located as a cluster on chromosome 1q21 (1-3). S100 gene expression predominantly takes

Correspondence to: Dr Cheng Luo or Professor Shanggui Deng, School of Food and Pharmacy, Zhejiang Ocean University, 1 Ocean University S. Road, Zhoushan, Zhejiang 316022, P.R. China

E-mail: luo58@yahoo.com

E-mail: dengshanggui@163.com

Key words: S100A4 dimerization/S100A4-NMIIA complex, A549 NSCLC cells, polysaccharide CP1, migration/invasion, scratch wound healing assay, Matrigel assay place in the bone marrow-derived cells, such as granulocytes, macrophages and monocytes, endothelial cells, and is involved in the cell cycle, differentiation, inflammation, mobility and mobility (4-7). S100 proteins serve important intracellular and extracellular functions (8). The proteins typically consist of homodimers, each monomer of S100 contains two helix-loop-helix structural domains, so-called EF-hand, calcium-binding domains, which are connected by a central hinge region. The high affinity binding to calcium of the C-terminal classical EF-hand domain induces a conformational change in the S100 proteins to expose a hydrophobic binding site for targeting a large number of proteins (9). S100 proteins are localized in the cytoplasm and/or nucleus, and may be involved in the regulation of cellular processes, including cell cycle progression and differentiation in a wide range of cells (10). The chromosomal rearrangements and altered expression of the $\mathrm{S} 100$ gene have been implicated in tumor metastasis. Over 50 target proteins have been identified to interact with various S100 proteins, including transcription factors, metabolic enzymes, kinases, annexins and contractile proteins (11). In general, the majority of these interactions are dependent on calcium signaling, however a subset of interactions is independent of calcium activation (12). S100 proteins are typically expressed in a tissue specific manner and their up or downregulation has been associated with numerous diseases, including several types of cancer (13). For example, elevated serum levels of S100 calcium binding protein B have been detected in patients with melanoma, and to be associated with metastasis and a poor prognosis $(14,15)$.

S100 calcium binding protein A4 (S100A4) is one of the multiple alternative splice variants of the S100 gene, creating a 109 amino acid protein $(12 \mathrm{kDa})$, particularly involved in cell mobility and motility. In vivo studies demonstrated that S100A4 was involved in the development of metastasis (16-19) and overexpression of S100A4 has been detected in various types of cancer, including breast, pancreatic, colorectal, ovarian, and prostate and lung cancer (20). S100A4 has also been widely detectable in blood samples from patients with inflammation, neoplasia or cancer. S100A4 protein expression has been suggested as a criterion for clinical diagnosis despite 
the potential for false positive results $(21,22)$. However, the high sensitivity of S100A4 to inflammation and metastasis has led to a potential target in cancer therapy, frequently by inhibiting the dimerization (23-25). However, the various mechanisms of S100A4 in and outside the cells are not fully understood. For instance, various types of cancer cells may adjust to respond to external factors such as polysaccharides. By examining the S100A4 protein structure, it has been demonstrated that carcinogenesis is particularly associated with the mobility and motility of S100A4 by aggregation with a non-muscle myosin IIA (NMIIA) tail fragment complex protein. The S100A4-NMIIA complex is the functional conformation for inducing migration (26-29). However, despite the inferences of an important role in cancer development, the mode of action of S100A4 proteins remains unclear.

A large number of foodborne or naturally derived compounds, particularly non-starch polysaccharides, have exhibited antioxidation activity in vitro (30-32) and inhibition of cancer cell migration and invasion (33-35). Our previous studies demonstrated that the coix polysaccharide CP1 fraction extracted from adlay seeds inhibits A549 cell proliferation and induces cell apoptosis via a mechanism primarily involving activation of the intrinsic mitochondrial pathway (36). The current study analyzed the inhibition of cancer cell migration and invasion by $\mathrm{CP} 1$, the association with the inhibition of S100A4 gene expression and the potential mechanism of the interference of the location of S100A4 targeted by a polysaccharide CP1 analog through in silico analysis.

\section{Materials and methods}

Preparation of coix polysaccharide, CP1, and cell culture. The CP1 polysaccharide was extracted from adlay seeds (C. lachryma-jobi L.) by decoction and alcohol precipitation as described in a previous study (36). The human A549 non-small cell lung cancer cell line was obtained from the Cell Bank of Type Culture Collection of Chinese Academy of Sciences (Shanghai, China) and cultured in RPMI-1640 medium (Invitrogen; Thermo Fisher Scientific, Inc., Waltham, MA, USA) supplemented with L-glutamine (1 mM), 10\% (v/v) heat-inactivated fetal bovine serum (FBS), penicillin $(100 \mathrm{U} / \mathrm{ml})$, and streptomycin $(100 \mu \mathrm{g} / \mathrm{ml})$ at $37^{\circ} \mathrm{C}$ in $5 \%(\mathrm{v} / \mathrm{v}) \mathrm{CO}_{2}$ incubator. In general, all experiments were conducted when cells reached $80-90 \%$ confluence. The cells were at $<20$ passages, remaining normal and with healthy cell morphology, and without mycoplasma contamination throughout the experiments.

Cell viability and proliferation. The effect of CP1 on the viability of A549 cells was assessed by MTT assay (36). Briefly, exponentially growing cells in 96-well plates were treated with different concentrations $(10-300 \mu \mathrm{g} / \mathrm{ml})$ of CP1 in complete RPMI-1640 medium. Control cells were cultured in medium not containing CP1. MTT $(20 \mu 1,5 \mathrm{mg} / \mathrm{ml})$ was added following incubation of the cells for 24 and $48 \mathrm{~h}$, and subsequently the cells were incubated for $4 \mathrm{~h}$. The medium was then aspirated and $150 \mu \mathrm{l}$ dimethyl sulfoxide (DMSO) was added into each well. The absorbance was measured at $570 \mathrm{~nm}$ using a 96-well microplate reader. All experiments were performed three times. The cell viability was calculated as follows: Ratio of cell viability $(\%)=(\mathrm{A}-\mathrm{B} / \mathrm{C}-\mathrm{B}) \times 100$; where A is the average optical density of CP1-treated cells, $\mathrm{B}$ is the average optical density of the control wells (culture medium without cells), and $\mathrm{C}$ is the average optical density of the negative control (culture medium containing DMSO and no CP1).

Cell scratch wound healing assay in vitro. The cell scratch wound healing assay was performed based on the Yarrow method (37). The cells were seeded in 24-well plates for $24 \mathrm{~h}$ and cell density reached $\sim 70-80 \%$ confluence as a monolayer. Gently and slowly, a scratch was made in the monolayer across the center of the well using a $1 \mu$ l pipette tip. While scratching across the surface of the well, the long-axial of the tip was always perpendicular to the bottom of the well. The resulting gap distance is therefore equal to the outer diameter of the end of the tip, and then the cells were washed with PBS buffer three times to remove cell debris. Scratch healing rate $(\%)=(0 \mathrm{~h}$ scratch width-12 or $24 \mathrm{~h}$ scratch width $) / 0 \mathrm{~h}$ scratch width $\mathrm{x} 100$ was photographically recorded and cell confluence area was measured to calculate the cell migration.

Cell invasion assay. A Transwell migration chamber assay was performed to observe cell invasion, particularly the motility capability of tumor cell transmigration across Matrigel in vitro. For the assay, $1 \times 10^{5}$ cells in FBS-free RPMI-1640 medium were plated in the top chamber of the Transwell insert with a Matrigel-coated polycarbonate membrane. RPMI-1640 medium with $10 \%$ FBS was added to the lower chamber as a chemoattractant. After incubation for $24 \mathrm{~h}$ (migration assay) or $36 \mathrm{~h}$ (invasion assay), cells on the lower surface of the membrane were fixed with $10 \%$ formalin and stained with $0.2 \%$ crystal violet. Cells that did not migrate through the pores were mechanically removed using a cotton swab (38). The images of migrated cells were acquired using an inverted light microscope at $\mathrm{x} 200$ magnification. The number of invaded cells was counted from five or six randomly selected fields in a blind manner.

S100A4 gene expression. Total RNA was extracted from $\sim 2 \times 10^{6}$ cells for each test using an RNeasy Mini kit (Qiagen, Inc., Valencia, CA, USA) according to the manufacturer's protocol. The integrity of the total RNA was determined electrophoresis on $1 \%$ agarose gel. Reverse transcription (RT) was performed using $1 \mu \mathrm{l}$ Ribolock $^{\mathrm{TM}}$ RNase Inhibitor, $1 \mu 1$ Oligo (dT) 18 primer, $2 \mu 110 \mathrm{mM}$ dNTP mix, $4 \mu 15 \mathrm{X}$ RevertAid reaction buffer, $2 \mu \mathrm{l}$ template RNA (100 ng/ $\mu \mathrm{l}), 1 \mu \mathrm{l}$ RevertAid $^{\mathrm{TM}}$ reverse transcriptase (Thermo Fisher Scientific, Inc.) and nuclease-free water was added to a final volume of $20 \mu \mathrm{l}$. Reagents were mixed, and incubated at $42^{\circ} \mathrm{C}$ for $1 \mathrm{~h}$, then at $70^{\circ} \mathrm{C}$ for $5 \mathrm{~min}$ to terminate the reaction. The cDNA was stored at $-20^{\circ} \mathrm{C}$. The polymerase chain reaction (PCR) product of S100A4 was detected using the primers listed in Table I, designed with Primer 3 software version 0.3.0 (frodo. wi.mit.edu). Primers were synthesized by Invitrogen (Thermo Fisher Scientific, Inc.). PCR of S100A4 was performed using $5 \mu \mathrm{l}$ 10X Taq reaction buffer, $2 \mu \mathrm{l}$ template cDNA, $1.5 \mu 1$ primers each (forward and reverse), $1 \mu \mathrm{l}$ dNTP mix (10 mM), $1 \mu 1$ Taq DNA polymerase (Promega Corporation, Madison, WI, USA) and nuclease-free water to a final volume of $50 \mu 1$. The reaction was performed at $94^{\circ} \mathrm{C}$ for $30 \mathrm{sec}$, then 35 cycles 
of $94^{\circ} \mathrm{C}$ for $30 \mathrm{sec}, 58^{\circ} \mathrm{C}$ for $30 \mathrm{sec}$ and $72^{\circ} \mathrm{C}$ for $45 \mathrm{sec}$, with final extension at $72^{\circ} \mathrm{C}$ for $10 \mathrm{~min}$, and then maintained at $4^{\circ} \mathrm{C}$. The PCR fragments were visualized on a $1.2 \%$ agarose gel stained with ethidium bromide, semi-quantitatively analyzed using an ImageQuant LAS 4000 (GE Healthcare Bio-Sciences, Pittsburgh, PA, USA), and sequenced by a commercial sequencing service company (Beijing Genomics Institute, Beijing, China) to identify it as S100A4.

Western blot detection of S100A4 protein expression. A549 cells were incubated to the logarithmic growth phase and $1 \times 10^{6}$ cells were synchronized for another $10 \mathrm{~h}$, then CP1 was added to a final concentration of 200 and $300 \mu \mathrm{g} / \mathrm{ml}$, and incubated for $48 \mathrm{~h}$. Cells were collected, washed twice with ice-cold PBS and lysed with lysis buffer [50 mM Tris, pH 7.4, 150 mM NaCl, 1 mM EDTA, 0.2 mM PMSF, $1.0 \%$ Triton X-100, protease inhibitor cocktail (Sigma-Aldrich; Thermo Fisher Scientific, Inc., Waltham, MA, USA)]. Lysates were incubated for $10 \mathrm{~min}$ on ice, sonicated and centrifuged for $15 \mathrm{~min}$ at $12,000 \times \mathrm{g}$. Subsequently, protein concentrations were determined using the Bradford assay and the samples were boiled for $10 \mathrm{~min}$. Equal amounts of protein (20 $\mu \mathrm{g} /$ lane) were separated by SDS-PAGE, transferred to nitrocellulose membranes and immunoblotted with a 1:1,000 dilution of a rabbit primary antibody against human S100A4 (catalog no. ab41532; Abcam, Cambridge, MA, USA) and 1:4,000 dilution of a rabbit primary antibody against human $\beta$-actin (catalog no. ab8227; Abcam) at $4^{\circ} \mathrm{C}$ overnight. The secondary antibody was a fluorescein-conjugated goat anti-rabbit $\mathrm{IgG}$ antibody (H+L; catalog no. 111-035-144; Jackson ImmunoResearch Laboratories, Inc., West Grove, PA, USA), diluted 1:5,000 in blocking solution for $1 \mathrm{~h}$ at room temperature. Immunoreactivity of PVDF membranes was visualized by scanning on LI-COR infrared laser imaging system (LI-COR, Inc., Lincoln, NE, USA). The values of the band density were normalized to $\beta$-actin using Multi-Gauge software version 2.0 (FujiFilm Corporation, Tokyo, Japan), therefore, the background was subtracted and only the non-saturated signals were quantified, resulting in a ratio which indicated the relative expression levels of the target protein for statistical analysis $(n=3)$.

Molecular docking of S100A4 and polysaccharides. The protein structure of S100A4 used in the docking studies was obtained from the Protein Data Bank (http://www.rcsb. org/pdb/home/home.do cod3CGA) $(21,22)$. All hydrogen atoms were added and the calcium ion, in each subunit, and an active site of a sphere was set around the following seven residues: Phe72, Tyr75, Phe78, Leu79, Met12, Val13 and Phe16, the coordinates of the sphere were 7.985, 6.865, -4.913. Iota-carrageenan (1CAR) was used as surrogate polysaccharide (37) for the simulation, it was energy minimized using 'Powell algorithms' method with a convergence gradient value of $0.05 \mathrm{kcal} /(\mathrm{mol} \AA), 100 \mathrm{max}$ interations were saved as mol2 format using the SYBYL-X 2.0 package (Tripos, Inc., St. Louis, MO, USA). Molecular docking was performed using GOLD 3.0.1 software (www.ccdc.cam.ac.uk/solutions/csd-discovery/components/gold/) that applied genetic algorithm. The number of generic algorithm runs was set to 10. Other parameters were the default.

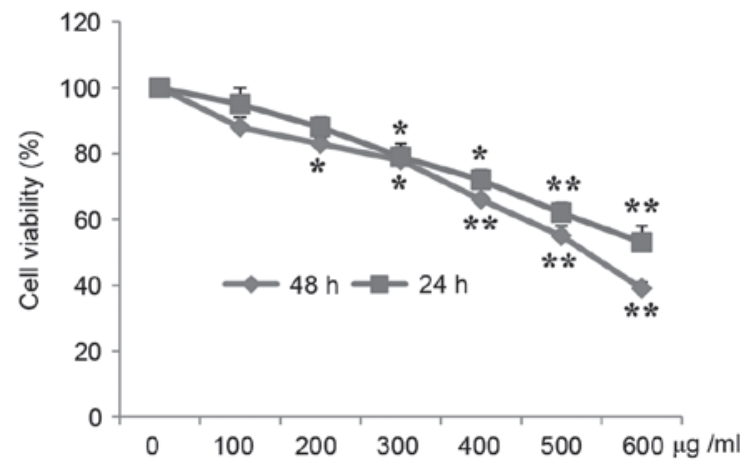

Figure 1. Effect of Adlay CP1 polysaccharides on cell viability of A549 non-small cell lung cancer cells $(\mathrm{n}=3)$. ${ }^{*} \mathrm{P}<0.05$ and ${ }^{* *} \mathrm{P}<0.01 \mathrm{vs} .0 \mu \mathrm{g} / \mathrm{ml} \mathrm{CP1}$.

Motility mechanism by analyzing the S100A4-NMIIA complex with $1 C A R$. The protein structure used in the docking studies was obtained from the Protein Data Bank (code 3ZWH). All hydrogen atoms were added, then the internal NMIIA peptide was removed. The polysaccharide in $1 \mathrm{CAR}$ was energy minimized using 'Powell algorithms' method with a convergence gradient value of $0.05 \mathrm{kcal} /(\mathrm{mol} \AA), 100$ max iterations, saved as mol2 format using SYBYL-X 2.0 package. Molecular docking was performed using GOLD 3.0.1 software that applied genetic algorithm, and the binding site was defined to encompass all atoms within a $10 \AA$ sphere, whose origin (point $16.579,1.084,23.581$ ) was located at the center of the residues at N-terminal of the NMIIA peptide (residues from Tyr1893 to Ala1907). The number of generic algorithm runs was set to 20 . Other parameters were the default.

Statistical analysis. SPSS 19.0 software (IBM SPSS, Armonk, NY, USA) was used for statistic analysis. All experimental results were expressed as the mean \pm standard deviation, and were analyzed by one-way analysis of variance with Dunnett's multiple comparison tests. $\mathrm{P}<0.05$ was considered to indicate a statistically significant difference.

\section{Results}

CP1 inhibits A549 cell proliferation. MTT assays demonstrated that A549 cell proliferation was significantly inhibited by $\mathrm{CP}$ in a time- and concentration-dependent manner. Fig. 1 presents the viability of cells treated with $\mathrm{CP}$ at various concentrations for 24 and $48 \mathrm{~h}$. The cell viability was reduced 84.11 and $76.33 \%$ of the control following treatment with 200 and $300 \mu \mathrm{g} / \mathrm{ml} \mathrm{CP}$, respectively, for $24 \mathrm{~h}$, and was 83.88 and $71.23 \%$ following treatment with 200 and $300 \mu \mathrm{g} / \mathrm{ml} \mathrm{CP}$, respectively, for $48 \mathrm{~h}$.

CP1 inhibits A549 cell migration. The effects of CP1 on cell migration were determined using a cell scratch wound healing assay. The cells gradually grow back to confluence over scratch wound and were almost healed in the control group after $24 \mathrm{~h}$. However, in the CP treatment groups wound healing was significantly reduced compared with the control $(\mathrm{P}<0.01)$, as shown my measuring the cell free area. Additionally, $300 \mu \mathrm{g} / \mathrm{ml} \mathrm{CP}$ exerted a more potent effect on cell migration compared with $200 \mu \mathrm{g} / \mathrm{ml} \mathrm{CP}$ following scratches. This 
Table I. Polymerase chain reaction primers and the products lengths.

\begin{tabular}{llr}
\hline Gene & \multicolumn{1}{c}{ Primers sequences } & Product length \\
\hline$\beta$-actin & Sense: 5'-AAATCTGGCACCACACCTT-3' & 646 bp \\
& Antisense: 5'-AGCACTGTGTTGGCGTAGAG-3' & 198 bp \\
S100A4 & Sense: 5'-TCAGAACTAAAGGAGCTGCTGACC-3' & \\
& Antisense: 5'-TTTCTTCCTGGGCTGCTTATCTGG-3' & \\
\hline
\end{tabular}

S100A4, S100 calcium binding protein A4.
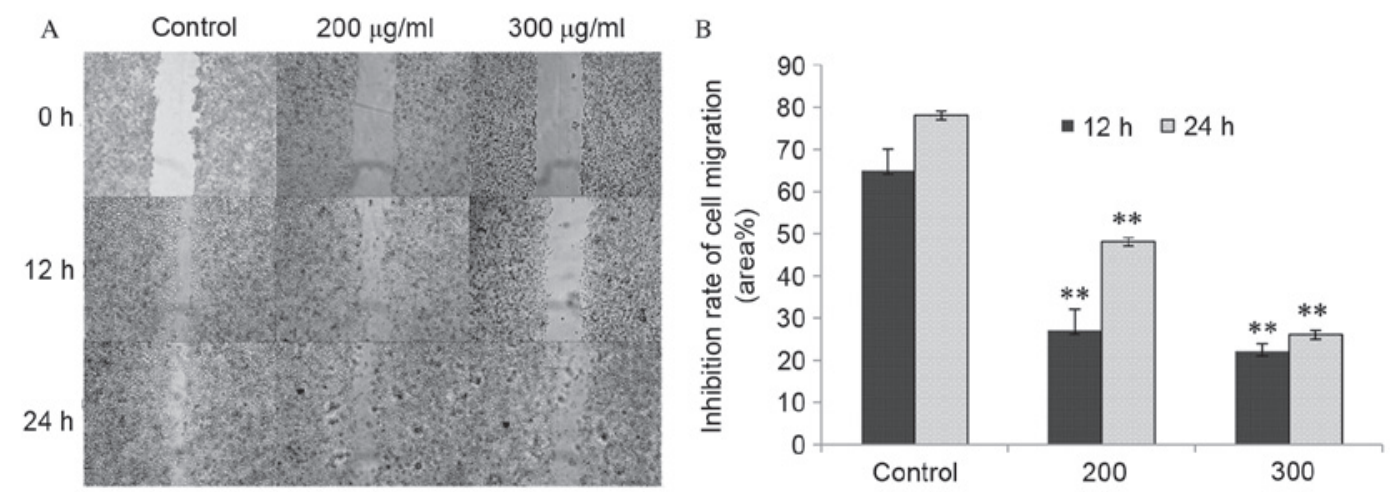

Figure 2. Inhibition of A549 cell migration by CP1. (A) The width of the scratch line was measured at 0,12 and $24 \mathrm{~h}$ (x40 magnification) to indicate migration of A549 lung cancer cells following treatment with 200 and $300 \mu \mathrm{g} / \mathrm{ml} \mathrm{CP1.} \mathrm{(B)} \mathrm{Inhibition} \mathrm{rate} \mathrm{of} \mathrm{cell} \mathrm{migration} \mathrm{was} \mathrm{calculated.} \mathrm{Values} \mathrm{are} \mathrm{presented} \mathrm{as} \mathrm{the}$ mean \pm standard deviation $(n=5) .{ }^{* *} \mathrm{P}<0.01$ vs. control.

indicated that CP1 inhibited cell mobility in a dose-dependent manner (Fig. 2).

CP1 inhibits invasion of A549 cells. Aggressive cancer cells can penetrate surrounding tissues or different organs by epithelial invasion, which directly and indirectly reflects clinical progression. The results of Fig. 3 demonstrated that, compared with untreated cells, as the CP1 concentration increases, the number of cells penetrating through the Matrigel was significantly reduced in a dose-dependent manner $(\mathrm{P}<0.01)$.

CP1 inhibits S100A4 gene and protein expression. Different concentrations of CP1 were incubated with A549 cells for $24 \mathrm{~h}$. The relative S100A4 mRNA level was significantly decreased compared with the control in a dose-dependent manner $(\mathrm{P}<0.01)$, which demonstrated that $\mathrm{CP} 1$ inhibited the expression of the S100A4 gene (Fig. 4). Western blot analysis was performed to detect the expression of S100A4 protein, which demonstrated that treatment with CP1 polysaccharides of $24 \mathrm{~h}$ inhibited the S100A4 protein expression in a dose-dependent manner $(\mathrm{P}<0.01$; Fig. 5).

Interaction with polysaccharides in the dimerization site of S100A4. Each S100A4 subunit contains two calcium-binding motifan N-terminal pseudo-EF hand and a C-terminal canonical EF-hand. The polysaccharide analog did not target the dimerization site as it was demonstrated that 1CAR interacted between the two helices from each subunit of S100 homodimers, stabilized by noncovalent that form an X-type four-helix bundle dimerization motif. With full flexibility to be as close as possible to a natural conformation of S100A4 (Protein Bank Database, 3CGA), 1CAR GOLD docking occurred in the dimerization site at the turning point of the amino acids Phe72, Tyr75, Phe78 and Leu79 of the H4 helix with Met12, Val13 and Phe16 of the H1 helix of the 2nd S100A4 dimer protein (Fig. 6). The 1CAR docking pocket was more clearly demonstrated with the molecular surface (Fig. 6B) compared with the helix (Fig. 6A). The three strongest bonds between S100A4 and 1CAR were scored at 20.26, 17.12 and 9.92, respectively, which indicate a low affinity, and weak interaction with the S100A4 dimer, however affinity may be markedly effected by in the situation of the electric charge, for instance when cell senescence, over oxidation or carcinogenesis occur (37).

Interaction of the S100A4-NMII complex with polysaccharides. The original setting (point 16.579, 1.084, 23.581) was located at the center of the residues at the N-terminal of the NMIIA peptide (residues from Tyr1893 to Ala1907), the number of generic algorithm runs was set to 20 . Other parameters were the default. 1CAR was targeted to S100A4 Asp-51 Arg-49 Gly-47 epitopes, revealing the potential for an intermolecular hydrogen bond by computational chemistry. The in vivo structure of S100A4 is associated with NMIIA protein. The most rigid portion of the structure is the $\mathrm{N}$-terminal half of the S100A4 chains (residues 2-44) with no marked differences between subunit A and B. These residues are partially involved in subunit-subunit interactions and in 

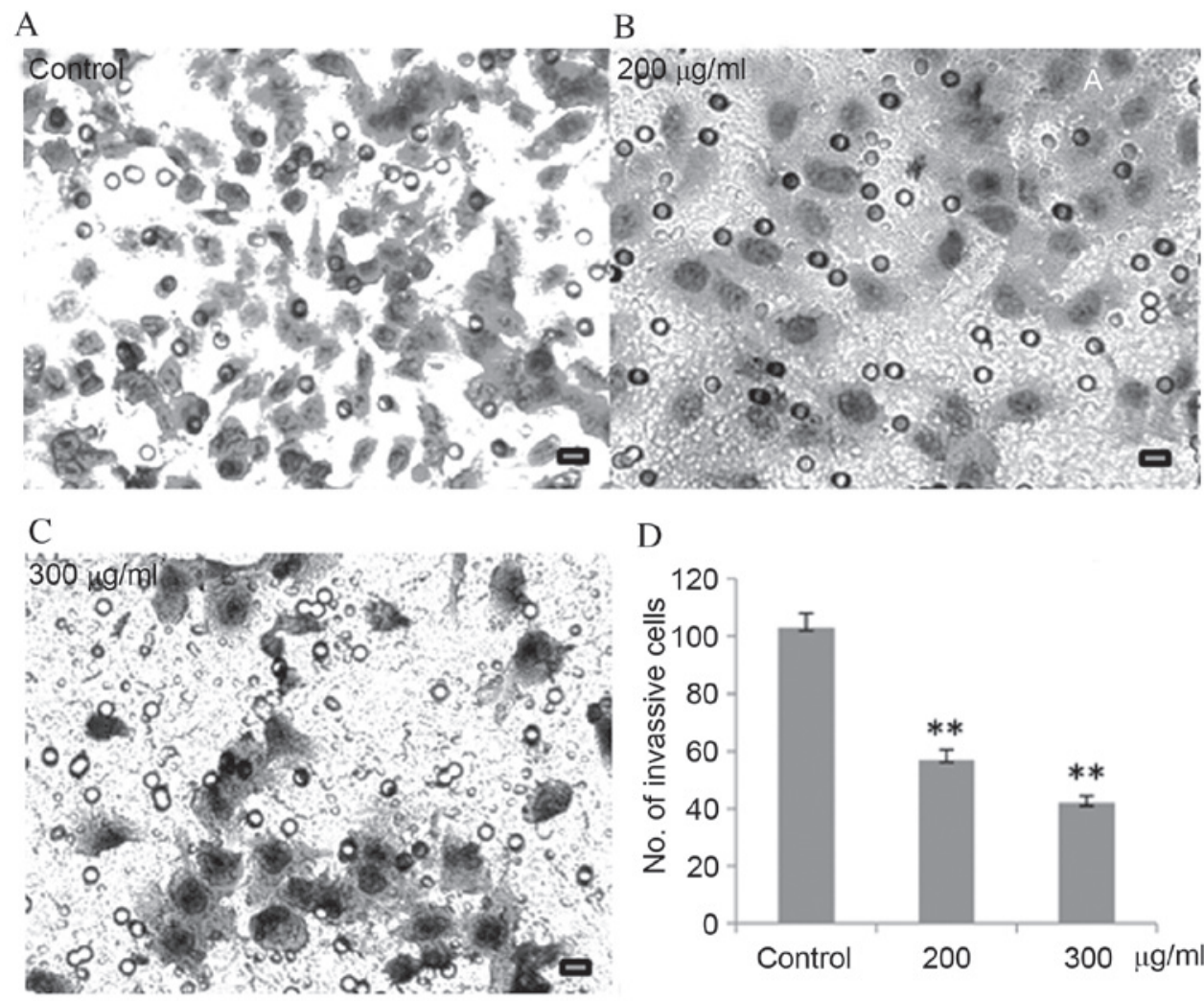

D

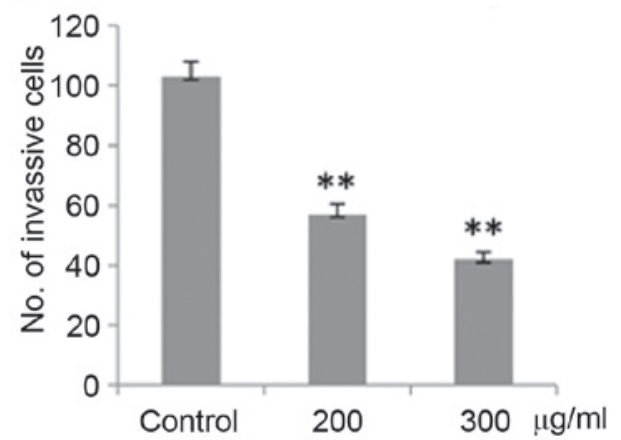

Figure 3. Inhibition of A549 cells invasion by CP1. Penetration of (A) control cells, and cells treated with (B) 200 and (C) $300 \mu \mathrm{g} / \mathrm{ml}$ CP1 through the Matrigel (hematoxylin and eosin staining; x100 magnification; scale bar, $10 \mu \mathrm{m}$ ). (D) Quantification of the number of invaded cells. Values are presented as the mean \pm standard deviation $(\mathrm{n}=3)$. ${ }^{* *} \mathrm{P}<0.01$ vs. control.

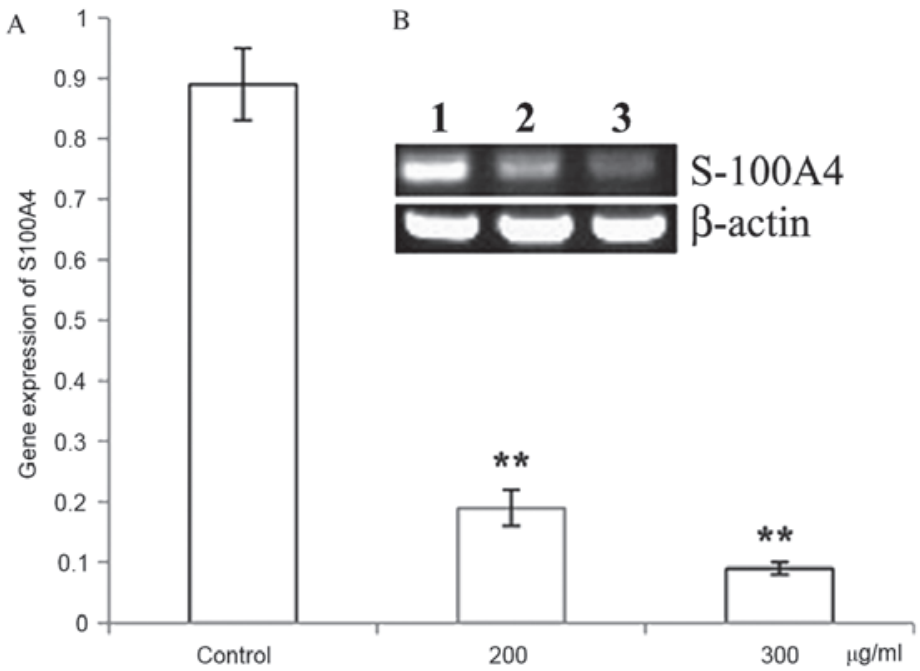

Figure 4. Inhibition of S100A4 gene expression by CP1. (A) Relative optical density of the S100A4 gene expression. Values are presented as the mean \pm standard deviation $(\mathrm{n}=3)$. ${ }^{* * *} \mathrm{P}<0.01$ vs. control. (B) Electrophoresis of reverse transcription-polymerase chain reaction products amplifying S100A4. Lane 1, Control; Lane 2, $200 \mu \mathrm{g} / \mathrm{m} \mathrm{CP1;} \mathrm{Lane} \mathrm{3,} 300 \mu \mathrm{g} / \mathrm{ml} \mathrm{CP1.} \mathrm{S100A4,} \mathrm{S100} \mathrm{calcium} \mathrm{binding} \mathrm{protein} \mathrm{A4.}$

forming the surface of the dimer on the diagonally opposite side to the NMIIA peptide tail binding interface (Fig. 7).

\section{Discussion}

The effect of coix polysaccharides, $\mathrm{CP} 1$, on cell proliferation was demonstrated to corroborate our previous results, which indicated that CP1 predominantly reduced cell viability by inducing apoptosis (36). Thus, the present study aimed to investigate how CP1 would influence cell migration and invasion, particularly the potential target genes involved.

S100A4 is localized in the nucleus, cytoplasm and extracellularly, and possesses a wide range of biological functions, including regulation of angiogenesis, cell senescence/survival, motility and invasion (39). S100A4 promotes metastasis in several experimental animal models, and 


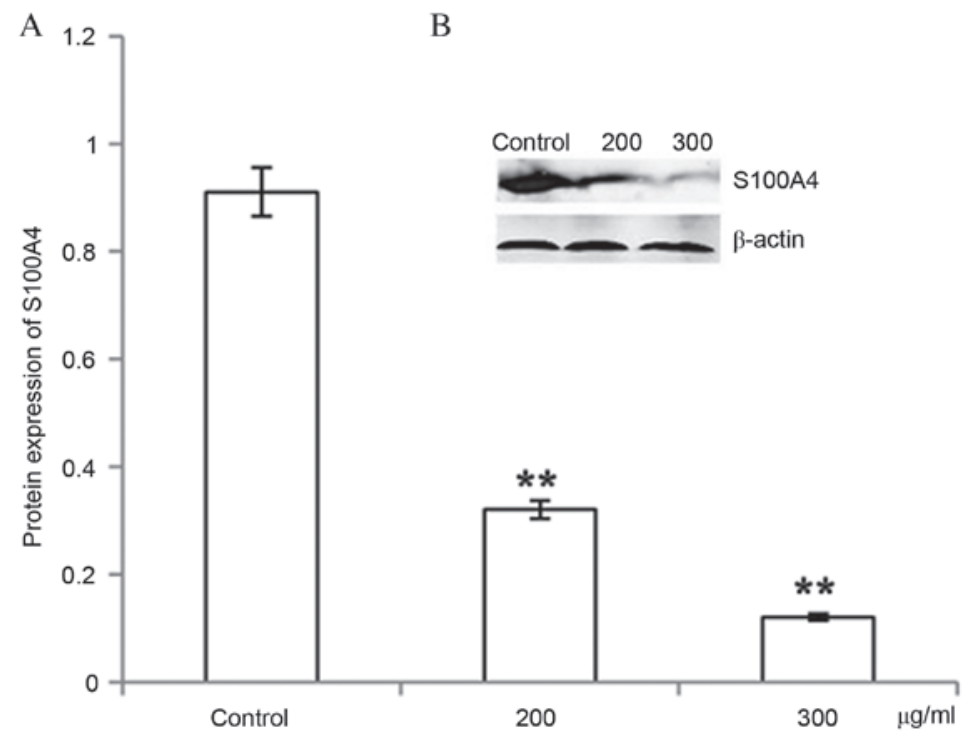

Figure 5. Inhibition of S100A4 protein expression by CP1. (A) S100A4 protein expression relative to $\beta$-actin. Values are presented as the mean \pm standard deviation ( $\mathrm{n}=3$ ). ${ }^{* *} \mathrm{P}<0.01$ vs. control. (B) Representative western blot. Lane 1, control; lane 2, $200 \mu \mathrm{g} / \mathrm{ml} \mathrm{CP1;} \mathrm{lane} \mathrm{3,} 300 \mu \mathrm{g} / \mathrm{ml} \mathrm{CP1}$. S100A4, S100 calcium binding protein $\mathrm{A} 4$.
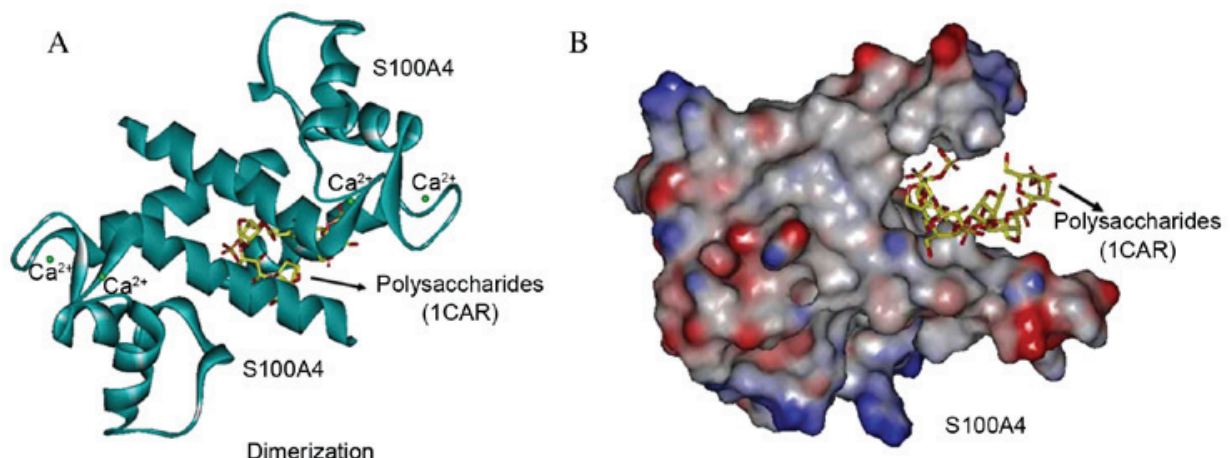

Figure 6. The potential interaction of S100A4 (Protein Bank Database, 3CGA) with 1CAR, the analog molecule of the polysaccharides. (A) Ribbon representation of the docking interaction between the 1CAR and the S100A4 dimer. (B) Surface representations of the docking interaction between 1CAR and the S100A4 monomer. The figure was prepared using Discovery Studio 2.5 (http://accelrys.com/). S100A4, S100 calcium binding protein A4; 1CAR, iota-carrageenan.

A

A S100A4

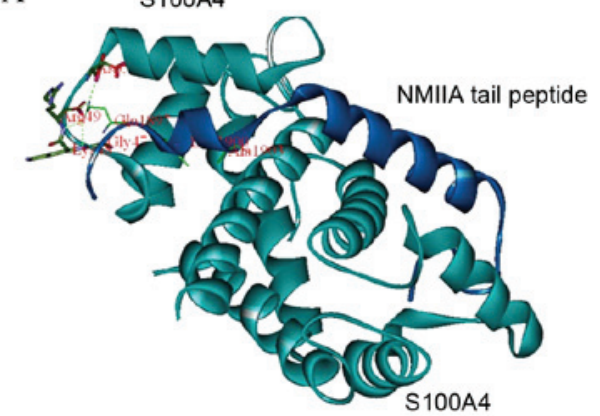

B

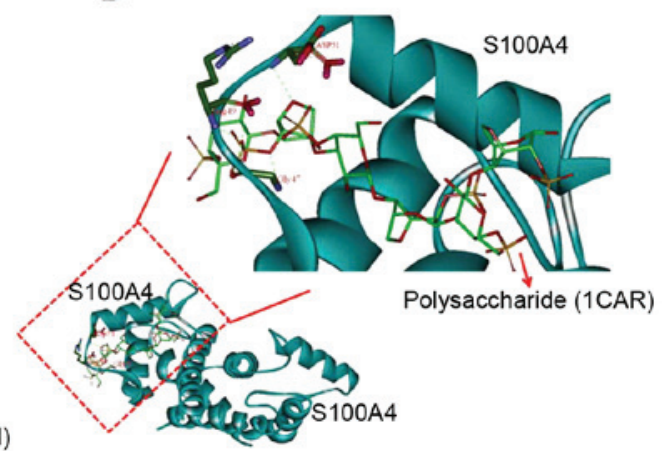

Figure 7. The molecular docking of the S100A4-NMIIA (3ZWH) complex with a surrogate polysaccharide, iota-carrageenan. (A) Crystal structure of S100A4-NMIIA tail peptide (Protein Bank Database, 3ZWH). (B) Docking conformations of 1CAR in S100A4 show that the 'O' atom of the sulfonyl hydrogen bonds with Arg49 and Gly47. The 'O' atom in the sugar ring hydrogen bonds with Asp51 similarly to NMIIA with S100A4. S100A4, S100 calcium binding protein A4; NMIIA, non-muscle myosin IIA tail fragment complex protein; 1CAR, iota-carrageenan.

S100A4 protein expression is associated with patient outcome in a number of tumor types (40). Thus, inhibition of S100A4 would be an applicable approach for cancer chemotherapy, particularly the compounds in food that may help to reduce, or reverse, the progression of metastasis without high toxicity or side effects. 
The mechanism of S100A4 as metastatic factor is unclear, even though its association with motility-associated proteins has being previously demonstrated (41). The inhibition of A549 lung cancer cell line proliferation in the presence of CP1 coix polysaccharide was repeatedly observed by MTT assay, and S100A4 expression was increased in the migratory and invasive cancer cells $(42,43)$. As CP1 inhibition of S100A4 was associated with inhibition of cancer cell migration and invasion, it is important further examine the precise molecular mechanism of S100A4 in mobility and motility. The data of the current study demonstrated that CP1 inhibited the migration of A549 cells in a scratch wound healing assay and Matrigel assay. Furthermore, S100A4 expression was reduced by $\mathrm{CP} 1$ as demonstrated by RT-PCR and western blot analysis. However, it remains unclear how the molecules interact in vivo. It is known that S100A4 acts in a complex of calcium-bound dimers and is secreted into the extracellular environment and the blood stream (34). It is also known that the effects of S100A4 on cell motility require interaction with NMIIA (44). Molecular docking simulation suggested that polysaccharide analog, 1CAR, interacted with one of the pockets of the S100A4 dimer, and interestingly the analog was able to dock to the N-terminal pocket of the S100A4-NIIMA complex, the site of the interaction S100A4 and NMIIA, even though the GOLD score was relatively high (26.04), the analog access to the pocket of the S100A4 dimer with an relative low free energy (20.26, 17.12 and 9.92).

The precise structure of CP1 is unknown, even though the polysaccharides in the extract are rhamnose, arabinose, xylose, galactose, galacturonic acid and glucuronic acid in molar ratios of 1.8:43.8:10.8:33.2:3.2:7.2 (45), however the molecular unity is low for the polysaccharides. Due to this reason a $1 \mathrm{CAR}$, a main cell wall polysaccharide of red algae was used as a CP1 surrogate for molecular docking analysis. Carrageenans are linear polymers of $\sim 25,000$ galactose derivatives with regular but imprecise structures, dependent on the source and extraction conditions. The iota-carrageenase bound to 1CAR fragments was resolved at 2.0A resolution (Protein Bank Database, $1 \mathrm{KTW}$ ), the first direct determination of a 3D structure of a polysaccharide (46). For simulation and simplification, the 6-mer polysaccharide, 1CAR, is widely used for the docking. The docking occurred at the interface of dimerization with the following 3D structural sequence: Phe72, Tyr75, Phe78, Leu79, Met12, Val13, Phe16; however the affinity with 1CAR was low.

S100A4 is frequently interacts with different proteins, and one of the most investigated interaction partners of S100A4 is NMIIA. Metastasis-associated cellular motility is associated with S100A4-NMIIA interaction (47). The calcium-dependent interaction of S100A4 with NMIIA prevents filament assembly and promotes filament disassembly $(8,10,28,29)$. The increased cytoskeletal dynamics lead to the formation of side protrusions and extensive forward protrusions in S100A4 expressing cells. S100A4 binds to the C-terminal end of the coiled-coil tail of NMIIA (31) overlapping the assembly competence domain. The complex of S100A4-NMIIA was demonstrated interact with polysaccharides in the current study.

Taking together all the above biological and docking simulation data, the inhibition of cancer cell migration and invasion by $\mathrm{CP} 1$ may be caused by interaction with S100A4. Even though the large molecules of polysaccharides interacted weakly, they exhibited a tendency and ability to inhibit S100A4, potentially due to de-dimerization or destabilization of the S100A4-NMIIA complex. CP1 may therefore have potential as an alternative cancer chemotherapeutic via targeting of S100A4. However, further studies are required to understand the precise mechanisms involved.

\section{Acknowledgements}

This work was financed by National Natural Science Foundation of China (grant no. 31471609), the International Science and Technology Cooperation Program of China (grant no. 2012DFA30600), the Special Program for the Science and Technology Plan of Zhejiang Province (grant no. 2011C02003).

\section{References}

1. Maletzki C, Bodammer P, BreitrÜck A and Kerkhoff C: S100 prteins as diagnostic and prognostic markers in colorectal and hepatocellular carcinoma. Hepat Mon 12: e7240, 2012.

2. Schäfer BW, Wicki R, Engelkamp D, Mattei MG and Heizann CW: Isolation of a YAC clone covering a cluster of nine S100 genes on human chromosome 1q21: Rationale for a new nomenclature of the $\mathrm{S} 100$ calcium-binding protein family. Genomics 25: 638-643, 1995.

3. Yamamura T, Hitomi J, Nagasaki K, Suzuki M, Takahashi E, Saito S, Tsukada $\mathrm{T}$ and Yamagchi K: Human CAAF1 gene-molecular cloning, gene structure, and chromosome mapping. Bichem Biophys Res Commun 221: 356-360, 1996.

4. Roth J, Vogl T, Sorg C and Sunderkötter C: Phagocyte-specific S100 proteins: A novel group of proinflammatory molecules. Trends Immunol 24: 155-158, 2003.

5. Guignard F, Mauel J and Markert M: Identification and characterization of a novel human neutrophilprotein related to the S100 family. Biochem 309: 395-401, 1995.

6. Marti T, Erttmann KD and Gallin MY: Host-parasite interaction in human onchocerciasis: Identification and sequence analysis of a novel human calgranulin. Biochem Biophys Res Commun 221: 454-458, 1996.

7. Ryckman C, Robichaud GA, Roy J, Cantin R, Tremblay MJ and Tessier PA: HIV-1 transcription and virus production are both accentuated by the proinflammatory myeloid-related proteins in human CD4+ T lymphocytes. J Immunol 169: 3307-3313, 2002.

8. Donato R: S100: A multigenic family of calcium-modulated proteins of the EF-hand type with intracellular and extracellular functional roles. Int J Biochem Cell Biol 33: 637-668, 2001.

9. Donato R, Cannon BR, Sorci G, Riuzzi F, Hsu K, Weber DJ and Geczy CL: Functions of S100 proteins. Curr Mol Med 13: 24-57, 2013.

10. Marenholz I, Heizmann CW and Fritz G: S100 proteins in mouse and man: From evolution to function and pathology (including an update of the nomenclature). Biochem Biophys Res Comun 322: 1111-1122, 2004

11. Orre LM, Panizza E, Kaminskyy VO, Vernet E, Gräslund T, Zhivotovsky B and Lehtiö J: S100A4 interacts with p53 in the nucleus and promotes p53 degradation. Oncogene 32: 5531-5540, 2013.

12. Ilg EC, Troxler H, Burgisser DM, Kuster T, Markert M, Guignard F, Hunziker P, Birchler N and Heizmann CW: Amino acid sequence determination of human S100A12 (P6, calgranulin C, CGRP, CAAF1) by tandem mass spectrometry. Biochem Biophys Res Commun 225: 146-150, 1996.

13. Cole AM, Kim YH, Tahk S, Hong T, Weis P, Waring AJ and Ganz T: Calcitermin, a novel antimicrobial peptide isolated from human airway secretions. FEBS Lett 504: 5-10, 2001.

14. Filipek A, Jastrzebska B, Nowotny M and Kuznicki J: CacyBP/SIP, a calcyclin and Siah-1-interacting protein, binds EF-hand proteins of the S100 family. J Biol Chem 277: 28848-28852, 2002.

15. Schäfer BW and Heizmann CW: The S100 family of EF-hand calcium-binding proteins: Functions and pathology. Trends Biochem Sci 21: 134-140, 1996.

16. Sherbet GV and Lakshmi MS: S100A4 (MTS1) calcium binding protein in cancer growth, invasion and metastasis. Anticancer Res 18: 2415-2421, 1998. 
17. Mazzuccheli L: Protein S100A4: Too long overlooked by pathologists? Am J Pathol 160: 7-13, 2002.

18. Gribenko AV, Hopper JE and Makhatadze GI: Molecular characterization and tissue distribution of a novel member of the S100 family of EF-hand proteins. Biochemistry 40: 15538-15548, 2001.

19. Taylor S, Herrington S, Prime W, Rudland PS and Barraclough R: S100A4 (p9Ka) protein in colon carcinoma and liver metastasis: Sssociation with carcinoma cell and T-lymphocytes. Br J Cancer 86 : 409-416, 2002.

20. Boye K and Maelandsmo GM: S100A4 and metastasis: A small actor playing many roles. Am J Pathol 176: 528-35, 2010.

21. Cerezo LA, Kuncová K, Mann H, Tomcík M, Zámecník J, Lukanidin E, Neidhart M, Gay S, Grigorian M, Vencovsky J and Senolt L: The metastasis promoting protein S100A4 is increased in idiopathic inflammatory myopathies. Rheumatology (Oxford) 50: 1766-1772, 2011.

22. Klingelhöfer J, Møller HD, Sumer EU, Berg CH, Poulsen M, Kiryushko D, Soroka V, Ambartsumian N, Grigorian M and Lukanidin EM: Epidermal growth factor receptor ligands as new extracellular targets for the metastasis-promotingS100A4 protein. FEBS J 276: 5936-5948, 2009.

23. Pathuri P, Vogeley L and Luecke H: Crystal structure of metastasis-associated protein S100A4 in the active calcium-bound form. J Mol Biol 383: 62-77, 2008.

24. Kiss B, Duelli A, Radnai L, Kékesi KA, Katona G and Nyitray L: Crystal structure of the S100A4-nonmuscle myosin IIA tail fragment complex reveals an asymmetric target binding mechanism. Proc Natl Acad Sci USA 109: 6048-6053, 2012.

25. Li ZH and Bresnick AR: The S100A4 metastasis factor regulates cellular motility via a direct interaction with myosin-IIA. Cancer Res 66: 5173-5180, 2006.

26. Tarabykina S, Scott DJ, Herzyk P, Hill TJ, Tame JR, Kriajevska M, Lafitte D, Derrick PJ, Dodson GG, Maitland NJ, et al: The dimerization interface of the metastasis-associated protein S100A4 (Mts1): In vivo and in vitro studies. J Biol Chem 276: 24212-24222, 2001.

27. Abdali S, Laere BD, Poulsen M, Grigorian M, Lukanidin E and Klingelhöfer J: Toward methodology for detection of cancer-promoting S100A4 protein conformations in subnanomolar concentrations using Raman and SERS. J Phys Chem 114: 7274-7279, 2010

28. Fang Z, Forslund N, Takenaga K, Lukanidin E and Kozlova EN: Sensory neurite outgrowth on white matter astrocytes is influenced by intracellular and extracellular S100A4 protein. J Neurosci Res 83: 619-626, 2006

29. Bettum IJ, Vasiliauskaite K, Nygaard V, Clancy T, Pettersen SJ, Tenstad E, Maelandsmo GM and Prasmickaite L: Metastasis-associated protein S100A4 induces a network of inflammatory cytokines that activate stromal cells to acquire pro-tumorigenic properties. Cancer Lett 344: 28-39, 2014.

30. Luo C, Urgard E, Vooder T and Metspalu A: The role of COX-2 and Nrf2/ARE in anti-inflammation and antioxidative stress: Aging and anti-aging. Med Hypotheses 77: 174-178, 2011.

31. Takahashi M, Konno $\mathrm{C}$ and Hikino H: Isolation and hypoglycemic of coixan A, B and C, glycans of Coix lachrymal-jobi var. Ma-yuen. seeds. Planta med 64-65, 1986.

32. Hsia SM, Chiang W, Ku YH and Wang PS: Downregulation of progesterone biosynthesis in rat granulosa cells by adlay (Coix lachrymal-jobi L. var. Ma-yuen Stapf.) bran extracts. Int J Impot Res 18: 264-274, 2006.
33. Baas P: Inductive and adjuvant treatment strategies for localized nonsmall cell lung cancer in operable and inoperable patients. Curr Opin Oncol 14: 180-184, 2002.

34. Yarrow JC, Perlman ZE, Westwood NJ and Mitchison TJ: A high-throughput cell migration assay using scratch wound healing, a comparison of image-based readout methods. BMC Biotechnol 4: 21, 2014.

35. Yao R, Davidson DD, Lopez-Beltran A, MacLennan GT Montironi R and Cheng L: The S100 proteins for screening and prognostic grading of bladder cancer. Histol Histopathol 22: 1025-1032, 2007.

36. Lu X, Liu W, Wu J, Li M, Wang J, Wu J and Luo C: A polysaccharide fraction of adlay seed (Coix lachryma-jobi L.) induces apoptosis in human non-small cell lung cancer A549 cells. Biochem Biophys Res Commun 430: 846-851, 2013.

37. Arnott S, Scott WE, Rees DA and McNabCG: Iota-carrageenan: Molecular structure and packing of polysaccharide double helices in oriented fibres of divalent cation salts. J Mol Biol 90: 253-267, 1974

38. Ma L, Teruya-Feldstein J and Weinberg RA: Tumour invasion and metastasis initiated by microRNA-10b in breast cancer. Nature 449: 682-688, 2007.

39. Pathuri P, Vogeley L and Luecke H: Crystal structure of metastasis-associated protein S100A4 in the active calcium-bound form. J Mol Biol 383: 62-77, 2008.

40. Van Deursen JM: The role of senescent cells in ageing. Nature 509: 439-446, 2014.

41. Kim YJ,Kim MA,Im SA, Kim TM,Kim DW, Yang HK, Heo DS Lee KU, Choe KJ, Kim NK, et al: Metastasis-associated protein S100A4 and p53 predict relapse in curatively resected stage III and IV (M0) gastric cancer. Cancer Invest 26: 152-158, 2008.

42. Garrett SC, Varney KM, Weber DJ and Bresnick AR: S100A4, a mediator of metastasis. J Biol Chem 281: 677-680, 2006.

43. Wang L, Gao S, Jiang W, Luo C, Xu M, Bohlin L, Rosendahl M and Huang W: Antioxidative dietary compounds modulate gene expression associated with apoptosis, DNA repair, inhibition of cell proliferation and migration. Int J Mol Sci 15: $16226-16245,2014$

44. Michel G, Helbert W, Kahn R, Dideberg O and Kloareg B: The structural bases of the processive degradation of iota-carrageenan, a main cell wall polysaccharide of red algae. J Mol Biol 334: 421-433, 2003.

45. Abrantes VE, Matias da Rocha BA, Batista da Nóbrega R, Silva-Filho JC, Teixeira CS, Cavada BS, Gadelha CA, Ferreira SH, Figueiredo JG, Santi-Gadelha T and Delatorre P: Molecular modeling of lectin-like protein from Acacia farnesiana reveals a possible anti-inflammatory mechanism in carrageenan-induced inflammation. Biomed Res Int 2013: 253483, 2013.

46. Bowers RR, Manevich Y, Townsend DM and Tew KD: Sulfiredoxin redox-sensitive interaction with S100A4 and non-muscle myosin IIA regulates cancer cell motility. Biochemistry 51: 7740-7754, 2012.

47. Elliott PR, Irvine AF, Jung HS, Tozawa K, Pastok MW, Picone R, Badyal SK, Basran J, Rudland PS, Barraclough R, et al: Asymmetric mode of $\mathrm{Ca}^{2+}{ }_{-} \mathrm{S} 100 \mathrm{~A} 4$ interaction with nonmuscle myosin IIA generates nanomolar affinity required for filament remodeling. Structure 20: 654-666, 2012. 